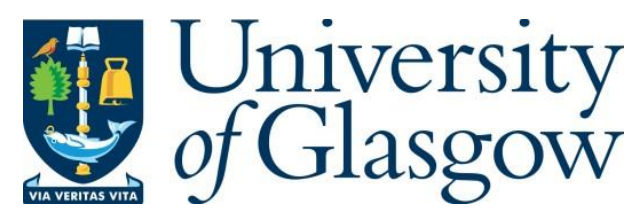

Gibb, K., McNulty, D. and McLaughlin, T. (2016) Risk and resilience in the Scottish social housing sector: 'We're all risk managers'. International Journal of Housing Policy, 16(4), pp. 435-457.

There may be differences between this version and the published version. You are advised to consult the publisher's version if you wish to cite from it.

http://eprints.gla.ac.uk/120089/

Deposited on: 17 June 2016

Enlighten - Research publications by members of the University of Glasgow http://eprints.gla.ac.uk 


\title{
Risk and Resilience in the Scottish Social Housing Sector: 'We're all risk managers'
}

\author{
Kenneth Gibb, Des McNulty and Tony McLaughlin ${ }^{1}$
}

May 2016

\begin{abstract}
Social housing providers confront an array of risks strategically and operationally. Recently, models of hybrid organisations have been developed to understand how nonprofit landlords are changing in response to market and other external pressures. In this paper we draw on a multidisciplinary conceptual framework of external and internal risks, multiple stakeholders and resilience strategies, as well as the notion of hybridity, in order to make sense of change in Scotland's social housing sector. The paper draws on elite interviews as well as case studies that seek to capture the range of approaches adopted by providers. Although providers handle and respond to risk in a variety of ways, risk management is a necessary part of the management of social housing businesses. Increasingly providers are concerned with questions of resilience the need to make themselves as organisations more resilient and also to promote greater resilience amongst tenants as a way of mitigating risk. Our research suggests that this is leading to some positive outcomes e.g. greater diversity within the sector and increased customer focus but there is concern that government polices remain siloed and are insufficiently flexible to deal with changed circumstances and the evolving needs and aspirations of the sector.
\end{abstract}

\section{Introduction}

This paper is concerned with the different ways Scottish social housing landlords are responding organisationally to critical but frequently unquantifiable changes in their operating environments. We seek to frame how effective these responses are in terms of risk, resilience, multiple stakeholders and the increasing hybridity of landlord activities. This process of organisational change is also a critical factor in shaping appropriate Scottish housing policy frameworks for non-market housing in a context where there is no clear vision or aim for social landlords within the housing policy setting.

Social housing is a long-term business. Existing tenants may stay with a landlord for decades and new developments are financed out of projected rents over possibly very long periods - 25 years or more. A stable policy framework, which the housing sector in Scotland enjoyed for quarter of a century prior to the financial crisis and the onset of

\footnotetext{
${ }^{1}$ Gibb and McNulty are at Policy Scotland, University of Glasgow; McLaughlin was formerly seconded to Policy Scotland from Glasgow Housing Association.
} 
austerity policies, is advantageous not least because risk or uncertainty increases the cost of borrowing. As we can see from recent developments south of the border, where the independent Office of National Statistics (ONS) has altered the classification of housing association to public non-financial corporations, the sector is very vulnerable to policy changes. ${ }^{2}$ [Scotland and the other non-English nations of the UK are to be examined by the ONS regarding re-classification in the fourth quarter of 2016: similar regulatory governance in Scotland makes reclassification the likely outcome].

Scottish social housing has been exposed to profound external shocks, most notably as a result of the financial crash, as well as the cumulative effect of policies such as the Right to Buy. There is acute concern also about the potential impact of welfare reform. The capacity of housing providers to understand and then manage these types of risk is partly governed by path dependency: their existing long term commitments shape their operations and reflect each organisation's mission. The capacity for resilience in the face of new and challenging risks is conditioned and sometimes constrained by the influence of diverse stakeholders who, at different points of time, have more or less power over the trajectory of the housing provider. Our argument is that the capacity to develop resilience in the face of these new risks and contexts is now a critical aspect of what social housing providers must do. However, as the evidence from our study shows, resilience practices take a variety of forms consequent on strategic choices made by different organisations within the sector. To the extent that a more diverse sector is better able to meet the needs of clients and the requirements of different places, there are benefits in greater heterogeneity. But diversity also creates challenges for housing policy and regulation, which are not adapting quickly enough to changes in the sector and the environment it operates in.

Our starting point is with these challenges facing the sector. After a long phase of relative stability, social housing is now facing multiple uncertainties, which necessitate strategic responses, both from individual providers and at sector level (XX, et al, 2015). First, the long-standing model of mixed funding for UK social housing (i.e. combining upfront capital grants with long term private finance) has been destabilised by the removal or massive reduction in availability of long term bank debt finance consequent on the financial crisis and by government austerity policies which have curtailed capital subsidy $^{3}$ and also put downward pressure on housing-related benefits. The pre-existing financial model is now unsustainable and neither the UK nor Scottish governments show signs of bringing forward a durable replacement. Second, unfolding welfare reform in the UK is starting to affect landlord income streams as many benefitdependent working age tenants face reductions in support, greater conditionality and a more punitive sanctions regime. Third, political and constitutional upheaval has created additional uncertainty for Scottish providers, given the different philosophies and policies of governments in power in London and in Edinburgh. There is little coordination between devolved governments and Westminster on housing matters. Fourth, a series of drivers: demographic, labour market and competition from private renting - all challenge longstanding assumptions about demand, opportunities for

\footnotetext{
${ }^{2}$ Inside Housing - Colin Wiles October 302015 'The beginning of the end?', http://www.insidehousing.co.uk/debate/expert-opinion/the-beginning-of-the-end/7012516.blog

${ }^{3}$ The Scottish government has retained high per unit grant levels for social housing (compared to other parts of the UK) and while there is a clear retained medium term commitment to new social supply, the overall programme for new supply is constrained by wider austerity pressures.
} 
growth and product range. These and other factors (e.g. regulatory statutory requirements to protect tenant interests) have led to a substantially different risk environment for social housing compared with a decade ago.

One important way that housing experts have tried to make sense of how providers are responding to the new climate makes use of the concept of hybridity. Providers who traditionally were essentially managers of social housing are taking on new roles that are combined with housing management (Mullins, et al, 2012). Instead of single purpose organisations they become hybrid organisations. Authors have identified apparent tensions arising between new commercial goals and more traditional social enterprise objectives in countries like the UK and the Netherlands (Gruis, 2008; Mullins and Pawson, 2010). While hybridity is an intuitively appealing concept, Mullins et al (2012, p.406) are surely right to echo Skelcher (2012) who agued that despite its widespread use, hybridity 'seems to play no useful function in theory building or advice to policy makers'. We agree with Mullins et al that the utility of such concepts is whether or not (and the extent to which) the concept of hybridity 'can clarify and theorise tensions that would have been otherwise opaque' (p.406). In order to define hybridity, Mullins et al go on (p.407) to highlight the importance of 6 hybrid features relevant to social housing: relatively persistent multiple stakeholders and significant characteristics of more than one sector but roots in one sector in particular. They also point to the importance of hybrid financial dependencies, hybrid governance structures and hybrid products and services.

As we indicate below, several of these six features are prominent in our risk/resilience framework developed in this paper. At the same time, Vincent Gruis and others have argued that hybridity amongst affordable housing providers or indeed sectors can be categorised and also trends indicated via a two by two matrix with the social versus commercial goals as one axis, and the contrast between social housing missions versus diversification into different lines of business, as the other. Responses to new risks have included diversifying into new business lines (e.g. market rented or care homes or factoring services), growing the business through organic or merger processes and shifting towards a more commercial orientation though for instance partnership with the private sector, finance or other parties.

Figure 1, based on Gruis (2008; Priemus and Gruis, 2011), is a set of social housing archetypes based on the Dutch experience. Diversification is described in terms of the axis between Defender (social housing management focus) and Prospector (diversification). Priemus and Gruis argue that Dutch social housing moved from the top left quadrant towards the bottom right although there was also movement towards the other two boxes. The matrix allows us to map where different national systems and indeed individual providers within a diverse sector are located and in which direction(s), if any, they are moving. Care is needed with how the matrix is used - it does not serve as a measure of hybridity and we need to be very careful to avoid the suggestion that greater hybridity is our preferred direction of travel for the sector, as there is insufficient evidence so far to demonstrate that the more hybrid an organisation is the better placed it might be to weather storms. But the matrix does provide an illustrative framework to account for the different approaches being taken in the sector. 
Figure 1 here

One perspective on hybridity is that it is both a response to and an outcome of more or less considered strategic resilient responses by providers to the risks and uncertainties they perceive they face in the short to medium term, as well as their array of influencing stakeholders and path dependencies. We can also argue that hybrid choice outcomes are themselves a subset of a wider range of questions that are essentially about the industrial organisation (IO) of non-profit housing providers [Gibb and Nygaard, 2006; Gibb, 2013]. Different responses to the IO choices facing providers will also help explain hybridity outcomes in the 2 by 2 diagram above and also preparedness to face new risks and to be resilient.

In this paper we will explore these ideas about risk, resilience and hybridity set against the Scottish social housing sector. Our fundamental research questions are, first, which resilience strategies, including changing hybrid structures, are being developed by the sector and by case study providers in Scotland in response to the new risk or emerging risk environment? Second, to what extent do the models applied in this paper help to inform this understanding?

The authors carried out a yearlong study of the contemporary social housing sector in Scotland framed in terms of resilience to emerging risks and challenges. The study built on an earlier paper by two of the authors (XX and YY, 2014) and an earlier international study of larger affordable housing providers in the UK, Canada, Australia and Norway (Maclennan and Chisholm, editors, 2013), which also involved one of the research team directly. The most recent project intended to construct an overview of the sector as a whole and involved an international evidence review, in-depth elite interviews with a representative cross-section of leaders of the sector, four diverse detailed case studies of social housing organisations, and two meetings of a sounding board of senior housing professionals (see: XX, YY and ZZ, 2015).

The structure of the paper is as follows. After the introduction, we unpack the multiple notions of risk and resilience and build a simple conceptual framework that attempts to capture the essence of the relationship between risk, hybridity, multiple stakeholders and resilience in the contemporary Scottish social housing sector. Sections 3 and 4 report evidence on, respectively, elite semi-structured interviews and the four case studies. Section 5 is a concluding discussion that relates the evidence back to the conceptual framework and assesses the wider implications of the paper's findings.

\section{Social housing in Scotland}

Housing policy has been devolved to Scotland since 1999 and there has been significant divergence from the rest of the UK subsequently, for instance, the ending of the right to Buy in Scotland and its distinctive progressive homelessness legislation (Gibb, 2012). However, public spending rules, social security and elements of housing taxation remain 
reserved at UK level ${ }^{4}$. Social housing has declined as a share of all households from $32 \%$ in 1999 to 23\% in 2013 (Scottish Household Survey, various) and like the rest of the UK, private renting has grown over this period (from 5\% to 13\%). In March 2011 there were 320,000 council homes and 275,000 housing association homes (Audit Scotland, 2013).

In Scotland social housing primarily consists of local authority (council) housing in the public sector and third sector, often charitable, non-profit housing associations (also known as Registered Social Landlords - RSLs). Housing is allocated according to need criteria, rents are set well-below market rents and tenancies are generally secure. Low income tenants, not just those not in employment, may receive income-related benefits to help pay for some or all of their rental costs. In Scotland, Government has a 'pot' of capital funding that provides grants for new build social housing, broadly equivalent for councils or housing associations ${ }^{5}$ and these are considerably more generous per unit than in England. However, the overall programme size is constrained and new social and affordable supply (mainly low cost home ownership) is insufficient to meet commonly accepted levels of overall housing need. In a major new study of housing need in Scotland, and set against a context of sluggish housebuilding, rising housing costs and household projections, Powell, et al (2015) estimate that core overall annual affordable housing need has increased by about 50\% from around 8,000 units in 2006 to about 12,000 units in 2015 (about twice the level of new annual affordable supply in Scotland from 2011-16).

Scotland has 26 council housing organisations 6 others transferred through whole stock transfer after tenant ballot, including Glasgow). There are more than 160 housing associations (and there are more if you include small specialist providers), which are made up of nearly 70 neighbourhood level community housing associations and cooperatives, plus rural specialists, regional and national bodies as well as larger specialist providers. In recent years there has been some intrusion by non-Scottish providers through merger, start-up and registration in Scotland as Scottish-registered subsidiaries. Scottish housing associations range in size from 200 units to around 40,000 .

While there is a comparatively small amount of diversification by housing associations into other forms of housing provision - mainly into low cost home ownership like shared equity shared ownership programmes, and, to a lesser extent, to affordable or mid market renting and related projects, this is not the main way they diversify their activities $^{6}$. Rather, many housing associations are adopting wider community anchor roles, in some cases supporting employment and employability of their residents and also supporting communities through welfare advice, financial inclusion and other related activities.

\footnotetext{
${ }^{4}$ The Scotland 2016 Act confers more powers to the Scottish Parliament and this includes powers to alter the housing cost elements of the main working age social security benefit, Universal Credit. This is a significant devolution of social security to Scotland and is both a considerable challenge in terms of implementation but also has implications for Scottish control over housing policy.

${ }^{5}$ Councils need less grant because they tend to own the land they build $\mathrm{n}$ and can access better terms for long term loans.

${ }^{6}$ Commercial diversification usually requires the establishing of a subsidiary and, if the provider is a charity, maintaining consistency with overall charitable aims. The Regulator may also have a legitimate say in the matter insofar as it affects the regulated part of the business and its tenants.
} 


\section{Risk, Resilience and Social Housing}

\section{The Multiple Meanings of Risk}

The concept of risk can have many meanings and layers. The Oxford dictionary defines risk as "a situation involving exposure to danger" 7 . However the notion of risk can embrace upsides as well as downsides e.g. financial returns to a risky economic prospect may be positive and profitable, rather than negative or loss making.

Assigning a numerical value to risk based on the probability of an outcome has become the cornerstone of the managerial technique of risk management which many businesses, including social enterprises, have adopted. Risks are eventualities that can be anticipated, measured and mitigated against. Mainstream economists make behavioural assumptions and identify preferences about risk averseness, risk neutrality or even a preference for risk-taking - without worrying about the implications of genuine uncertainty or indeed how to make reasoned decisions based on risk in practice (Wilkinson, 2008). Their interest is not in the dangers posed by a specific risk, but how an individual or organisation behaves in response to risk more generally. Classical writings on risk from an economic perspective include those of Knight (1921) and Keynes (1937). The former famously did distinguish between risk and uncertainty by arguing that unlike risk, uncertainty meant that that there was not enough information with which to assign numerical probabilities to future outcomes. Keynes took this argument further by distinguishing that which is certain from that which is probable. Decision-makers must accept that they live in a world that is characterised by uncertainty.

Other writers, following Beck (1992), have viewed risk as a social construction rather than a probabilistic calculation. It is the perception of risk, rather than the likelihood of something happening, which ultimately matters to the public consciousness. Zinn and Taylor Gooby (2006) argue that possible catastrophes, such as environmental damage linked to climate change, loom large in many people's minds, even though we may be safer from physical danger than ever before ${ }^{8}$. Pressure on the state to regulate and control risk is not always consistent with the objective dexposure to danger. In the context of social landlords, risk is about the assessment and management of the dangers to social housing organisations and their customers. In the course of the interviews for this project, a clear theme was a heighted awareness of risk and the proactive use by social landlords of risk management techniques such as risk registers.

In the course of the study, several respondents mentioned Cosmopolitan Housing Group. Cosmopolitan was an English social housing organisation that, having diversified by investing in the provision of student accommodation, failed to manage the risks involved appropriately and proportionally. It came to the attention of the English Social Housing Regulator that Cosmopolitan was experiencing cash flow problems and therefore faced possible financial collapse. Cosmopolitan was ultimately rescued by becoming part of the Sanctuary Group in March 2013. ${ }^{9}$ According to a follow-up report

\footnotetext{
${ }^{7}$ http://www.oxforddictionaries.com/

8 This is in fact a different representation of a phenomenon well known to behavioural economists - the 'saliency bias' where individuals over-estimate the significance of the familiar or known

${ }^{9}$ One of the authors was a board member of Sanctuary Housing Association during this episode.
} 
commissioned by the English Regulator the cause of the collapse at Cosmopolitan was a serious failure of governance within the organisation over a number of years, with previous regulators in England failing to appreciate the severity of the risks within Cosmopolitan. The report concluded that had regulation in the early 2000s been more comprehensive, the crisis might have been avoided. (Underwood, Kane \& Appleby, 2014)

Given that the Cosmopolitan situation was not just an organisational failure but also a systemic one, it has additionally affected the approach of the Scottish Housing Regulator (SHR). The SHR has published advice to social landlords on "Financial Risk and Viability". The SHR repeatedly stresses in its advice that RSLs need to maintain a strong focus on financial health and financial sustainability. It sees its statutory role in terms of protecting tenants from management failings - either through increased rent or reduction in services provided - and insuring that any adverse impact is minimised. It sees a key role for the governing body of each association as being to challenge management and to get assurance that everything possible is being done to manage the risk to financial health. It is within that context that the SHR has a clear regulatory expectation that RSLs will have robust business planning and risk management processes in place.

Landlords also confront internal risks as a result of path dependency and previous decisions with long-term consequences (e.g. development programmes with specific built forms or expensive contractual commitments). At the same time, as identified by Mullins, et al (2012), social housing providers face multiple stakeholders, which, because of their ambiguous position between the voluntary sector and the public sector - can at different times and in different sub-sectors play a major influencing role shaping the direction of specific providers and the wider sector. Key stakeholders are: the Scottish Housing Regulator who has the power to remove boards and senior staff (there are also charity and care regulators); the Scottish Government who set the policy framework, provide capital subsidy and the wider investment programme; the UK government sets taxation, benefits and broader banking/financial regulations; lenders and capital markets who set terms, conditions and covenants for social providers; contractors and other partners, plus local government, resident communities and tenants. The notion that social landlords are, in some sense, free to pursue their goals need to be heavily qualified. However, it would also be incorrect to say that agency plays no role in shaping the strategy and major decision-making of Scottish social landlords.

\section{Resilience}

Zolli and Healy (2012) show how the concept of resilience can be used to refer to economic, ecological, social or technical systems and to both people and organisations. They define resilience as:

"...the capacity of a system, enterprise or a person to maintain its core purpose and integrity in the face of dramatically changed circumstances" (Zolli and Healey, 2012, p8)

Another way of interpreting the concept is focused on the adaptability of an organisation. Hamel and Valikangas (2003) point to an organisation's ability to go beyond merely responding to setbacks as being fundamentally important to ensuring its 
resilience and consequently, its success: "strategic resilience is not about responding to a one-time crisis. It's not about rebounding from a setback. It's about continuously anticipating and adjusting to deep, secular trends that can permanently impair the earning power of a core business. It's about having the capacity to change before the case for change becomes desperately obvious" (p3).

The theme of continually reviewing and examining an organisation's strategic purpose was to the fore throughout our project. Almost everyone interviewed referred to flexibility as one of the characteristics that a resilient organisation should display. Flexibility in this context means that organisations can adapt and have the necessary financial arrangements and controls in place to meet the many challenges that the housing sector faces.

Taylor (2013, p.5-6) sets out her understanding of the different meanings of resilience as they relate to Scottish housing associations. Taylor defines resilience relating to business, psychology and ecology as:

- Business (continuity): the ability of an organisation's business operations to rapidly adapt and respond to internal or external dynamic changes and continue operations with limited impact on to the business

- The ability to recover quickly from illness, change or misfortune, in other words buoyancy or an ability to bounce back

- The ability to resume original shape or position after becoming bent, stretched or compressed - elasticity

- The process of recovery - to learn/adapt to difficulty, to have the capacity to respond to a disturbance

- The ability to absorb disturbances - to re-organise and still have the same identity.

Similar arguments are made by Hamel and Valikangas, who note "momentum is not the force it once was" in ensuring an organisation's success and that resilience requires "a capacity for continuous reconstruction". (2003, p4)

Like risk, the concept of resilience is multi-layered and multi-dimensional and can be applied in different ways. In housing, the term can be used in the context of a customer, a leader or a frontline member of staff. It can also be used to describe the characteristics of an organisation or even the housing sector as a whole. A resilient organisation is one that has the correct people with the correct skills. Individual resilience underpins organisational resilience.

\section{A Conceptual Framework}

Figure 2 sets out a simplified diagrammatic framework. At the centre are housing providers who are influenced or 'shocked' by external risks, which by definition they have no control over. Housing providers also face internal risks - the consequences of earlier decisions about their housing stock and committed investment and financing plans, their focus (i.e. where they are in the hybridity matrix) as well as industrial organisation decisions for which the transactions costs of changing direction are nontrivial. These are all forms of path dependency. 
The provider has to manage the needs and requirements of different stakeholders including government, tenants, the regulator, lenders and partners. Housing associations inhabit an ambiguous territory of ownership, governance and influence. They are not public bodies but government and the regulator exhibit large degrees of control, limiting association's discretion over what they can do. Multiple stakeholders at different times and for various reasons can wield considerable influence over the sector as a whole, as well as over particular providers. As the diagram indicates, stakeholder action may force or catalyse reforms on the sector, such as the regulatory requirements that were stepped up in the wake of the Cosmopolitan episode.

Figure 2 about here

The housing provider in different ways confronts these risks and challenges by seeking to develop and implement resilient responses. In the discussion of the case studies we will see different examples of these resilience mechanisms. Efforts to increase resilience are associated with a series of organisational reforms and these may, though not necessarily, suggest a movement within the hybridity matrix. In the rest of the paper we apply this framework as a heuristic simplification of the world faced by housing providers.

\section{Elite Interviews}

The project team carried out interviews with 16 senior people who had different levels of strategic roles within the Scottish social housing sector. The interviews were conducted in the months just before the Scottish Independence Referendum (September 18 2014).

\section{Confronting New Risks}

All interviewees cited welfare change as a key external risk: "on-going welfare changes are obviously a key risk, or set of risks in terms of our sector's income and in terms of the income of our customers. Related to this is rising rent arrears, which is a key risk and something that perhaps we struggle most on". (RSL Director)

As a result, landlords were obliged to invest in the resilience strategy of a much greater level of customer intelligence, as well as a cultural shift towards working with partner agencies and council departments "...landlords have gotten closer to tenants...That sense partly of actually just all the chapping of doors that's happened in the last 2-3 years to find out who is living in the properties which landlords have got to be honest and say they weren't on top of" (Senior RSL figure). These changes have been both labour intensive and promoted staff culture change. There was also a recurring theme that many of these changes would have been likely to come about in any case, but concern about the new operational environment had hastened their introduction. 
Pension underfunding was a key external risk for smaller RSLs in regard to financing pensions and the burden that they would place upon them moving forward. On more than one occasion it was proposed that many in the sector have not yet faced up to the issue. "We are going to reach a critical stage in terms of pensions. In saying that, I get no sense of inertia in terms of organisations pushing the issue to the background, but at the same time it is a major issue and risk for the sector" (Senior RSL figure).

There was also internal succession planning risk consequent on the retirement of long serving senior staff whose experience would be hard to replace and also the difficulty in recruiting a new generation of committed voluntary Board members who would be able to deal with the new complexity facing organisations. "There is also an issue around governance risk. New blood is certainly needed in this area with the skills and commitment to make a real contribution" (Senior RSL figure).

\section{Risk and its Management}

Risk is at the forefront of the minds of leaders in the housing sector. Organisations had generally put a lot of resilience focus on increasing awareness of risk and risk management/mitigation to insure that managing risk is no longer the 'job' of one senior person within the organisation. As one RSL Director put it (speaking of senior staff) - "If you can't describe the high level risks you shouldn't be in the job". One interesting view was also that there is an inherent risk in being too risk averse - that being so aware of the risks that are confronted that it impacts on levels of ambition.

There was a perception that RSLs should consider risk in a wider societal sense as well as the narrow organisational context. The hardship that people are experiencing means that housing organisations and their partners will have to pick up the pieces with diminished resources. This in turn made the range of risks more complex than they were previously. "The key risks are to people's incomes. This isn't just about welfare reform but it's about pressure on tenants incomes from across the board, for instance energy and food prices and everything else. That's as big a risk for our organisations but it is also more like a social issue. It puts all our services in a difficult position". (Representative organisation leader)

Having the right governance, structures, staff and culture in place were seen as particularly important dimensions of resilience. "When I think of organisations like Cosmopolitan down south, you think they didn't lack ambition but they lacked the ability to assess the risk and deliver against that ambition....That is the biggest risk and it also comes down to having the right governance and having the right skills and sophistication to be able to deal with that". (RSL figure Director) Another interviewee said: "In terms of culture, we're better than we used to be, we did have the tendency to plan for cataclysmic risks that never really happen but not plan for medium risks... we need to ensure that we have the right governance in place" (RSL Director).

\section{Resilience}

"[R]esilience is about being capable of dealing with change over the longer term... It's about being flexible but at the same time keeping one's own identity, and remembering the reasons why the organisations came together in the first place" (Representative 
organisation leader). An RSL director said: "organisational resilience is going to rely on sound governance, good and realistic planning" (RSL Director). The key to being resilient and self-aware is constantly reviewing and challenging your strategic purpose and mission, constantly reviewed to ensure that it is appropriate for the operational environment and customer base.

More than one interviewee referred to the need to promote "learning organisations". This was seen to be a key characteristic of resilience. "It's about having the right skills in place - as a membership association that is what we tend to focus on .... I see resilience as being about skills, knowledge and resources". (Representative organisation leader). A second view expressed was: "It is also the ability to get the organisation not to have to keep doing ad hoc things - i.e. we collect learning" (RSL Director).

\section{Relationships with Stakeholders}

There was a shared sense that a significant move towards working with stakeholders/partners had taken place. This was expressed in cultural terms, i.e. a willingness of housing organisations and providers of other services to work together, and also in tangible terms, i.e. in the establishment of new partnerships and ways of working with other agencies and other organisations. Arguably, this reflects the growing sense of mutual dependency between housing providers and key stakeholders This was despite the, at times difficult, nature and non-trivial transactions costs of negotiating and managing such partnerships.

However, it was also the case that: "Partnerships are hugely problematic - they are positive in the sense of what you are trying to get to the end. But in some ways you hate partnerships!...we have been reasonably ok in terms of sharing budgets but we still want to have some control in terms of how the outcomes go- and especially the timescales. This can be difficult...there are huge issues in partnerships - but huge benefits - that's why we go through the pain". (RSL Director)

There was a belief, particularly amongst RSL interviewees, that relationships with funders and the social security ministry (the Department of Work and Pensions or DWP) and, to a lesser extent with the Scottish Housing Regulator - were all undergoing fundamental change. "Clearly the relationship with funders has changed; we've not had major issues on that. But, what we know is that some funders have pulled out of the market, some of them have wanted to re-price for all sorts of things, and equally we have seen and have used some new entrants into the market". (RSL Director).

All interviewed felt that the relationship with DWP had become a fundamental one but there was also uneasiness in landlords being seen as being the arbiter in the introduction of the reforms. "...an emerging relationship is one around welfare reform, is around DWP, job centres and possibly around some of the other financial organisations to that extent... it's more about trying to build up products that would be of use to your customers" (RSL Director).

\section{Future Roles}


Social housing providers have to keep an eye on the future, because they are in a longterm non-profit business characterised by continuing and evolving relationships. "I think we can see that the sector is on a journey, and always has been.... Our role now is perhaps more as community leaders and anchor organisations". (Representative organisation leader)

There were some who viewed the role of the social landlord in fairly narrow terms (as defenders in terms of figure 1), as fundamentally a basic landlord function of collecting rent and letting houses: "We blur the role of the landlord at our peril". Another said: "One of the most important things that we have to hold on to is that we are landlords, we are not social workers...at the core of our business is a very simple transaction". (Senior local authority figure). A contrary view was also expressed: "I think there will be a divergence between landlords who simply look just to fulfil a landlord role and others who see themselves as having a much broader community role. There is not anything wrong with simply being a landlord but I hope that we certainly fall into the second category and fulfil a community role and provide a range of services that can make a real difference to our customers' lives". (RSL Director) This is more akin to the social innovator role in figure 1.

The tension or divide between returning to core functions or diversifying leads to different models. One RSL Director said: "If you look down south, they are much more used to diversification - you can see nursery schools, health centres, all those sorts of things. I'm not sure, I'm still struggling to see what they would bring to the business given the risks of this diversification...I think we would be more inclined to work with partners rather than delivering these things ourselves - diversity through partnership...Our growth strategy is to concentrate on what we are good at and then let's try and partner to deliver what we're not so good at, where we don't have that experience".

The 'choice' between returning to core housing functions versus future diversification is further explored in the case studies below.

\section{Case studies}

Different types of housing organisation were selected as case studies to examine how they manage risk and display resilience (summarised in Table 1). The four case study organisations comprise:

- A mid-sized (in Scottish terms) rural RSL (Albyn)

- A smaller community based urban RSL (Cassiltoun)

- A local authority landlord (Perth \& Kinross)

- A large group structure housing organisation (Wheatley).

This diversity was reinforced by the geographical spread of the case study organisations across different parts of Scotland. Each case study involved two principal stages examining risk register approaches and related strategy documents, and, secondly, interviewing key actors in the respective organisations regarding how they understand 
and respond to the new and emerging environment. The main themes discussed with each case study organisation concerned risk strategy, formal approaches to risk management and the wider approaches taken to resilience.

Table 1 about here

\section{Risk Strategy and Management}

All four had formal risk registers and strategies to manage risk and develop internal resilience strategies (see figure 2). Albyn had undergone several years of refreshing and training their board including making formal risk management central to the organisation. A senior officer said: "the training explained that we are all risk managers anyway. It was no longer seen as a 'Finance Director' thing. It hasn't got to the rest of the staff yet, but that is the next stage".

In the community-based association, Cassiltoun's approach to the key external risk of welfare reform was summarised by the following: "we've seen a lot of changes in the housing sector over the past 30 years including benefit changes and whilst the current changes are the most severe we believe our preparation, staff resources and business planning will help reduce the risks we face from welfare reform. Not only have we identified Welfare Reform as our number one risk we have also included welfare reform as a key operational objective".

Perth and Kinross council focused on the staffing implications of the work pressures created by the new risks: "Income is fundamental. I think this is connected to our own staffing position in being able to cover work, because there is an increased workload, and we are all working more widely, and there is probably fewer staff to do this. Like everyone else we have had budget cuts, so that is a risk...It's keeping up with this. We have all had reductions to staffing and increasing pressure. It's then how you actually continue to deliver the services while managing all the other stuff'.

Wheatley has explicitly sought to inculcate risk management throughout the organisation. Developing an organisation risk 'culture' has gone well beyond formal auditing of risks. "What we have tried to do is to get on their (staff specific) level and say that (managing risk) is what we do every day...that is why we have provided guidance. Guidance is key because for most people it's already in their head anyway; it's easing it out of people". Developing the culture, however, is an on-going challenge and communication is fundamental. This can be seen in comments by members of the risk audit team: "We have strong Board buy in [but] ...there still needs to be more ownership further down the organisation".

\section{Resilient?}

Organisational attitudes and those of staff were perceived to be important to Wheatley's resilience, as exemplified by their 'Think Yes' campaign to empower front line staff.: 'It's about being a problem solving organisation, having a whole kind of 'can do' attitude 
where anything is possible - it very much starts with front line officers, where they can change services at the point of demand. That is the most important because that is where we maintain our reputation and customer satisfaction".

Establishing the Wheatley group structure was itself fundamentally an exercise in resilience, for instance, in being capable of sourcing alternative sources of funding: "There's quite a bit about our funding structures, how you negotiate funding agreements. We've set this up so that each of the subsidiaries can draw down as required, so each of the subsidiaries supports each other so everybody is in it together, but at the same time each subsidiary is responsible for not letting the other subsidiaries down in financial terms. This funding structure certainly gives us more".

For the council landlord (Perth \& Kinross), flexibility and partnership were key principles of resilience. "I think stripping it back to basics, it is about being flexible about the things that come your way". On partnership working in Perth \& Kinross :"We've been heavily involved with Education and Children's Services....this collaboration is very much about securing positive outcomes for our children and to contribute to all the big health outcomes as well... what can we do as a housing service - what is our contribution to this agenda? ... It's the wider contribution to national outcomes - in the last few years this is something that has really moved on".

For Albyn and Cassiltoun, governance reforms were key to resilience. In Cassiltoun's case they focused on Board membership from the local community. There is an induction, training and development plan for new and existing Board members which equip them with the skills to effectively carry out their role. In 2014 an independent governance review created an action plan to further improve training and skills and to also further consider specialist or professional recruitment of Board members in the future. Cassiltoun also see resilience coming from sound business planning in particular, from their 30 year Business Plan which is reviewed annually. However resilience for Cassiltoun is also about being on the front foot and being close to customers. Cassiltoun concluded that this isn't a new thing, however, as this is what the organisation has always been focused on. Albyn stressed good governance, openness and transparency but also sensible diversification into other activities that could both generate income and create employment and training opportunities.

\section{Diversity and Commonalities}

Welfare reform was viewed a significant risk to the performance of organisations and the viability of business plans. There were, however, different opinions on the extent of this risk. Resilience for all revolved around: sound business planning, effective governance, partnership working, and being characterised as a learning organisation. These themes mirrored what was found to varying extents across other elements of research for this study.

We can reflect on the case studies in terms of the matrix in Figure 1 regarding socialcommercial orientation and whether social housing providers would diversify or stick to more core activities. The case studies do not of course fit neatly into the archetype cells - nonetheless, each case study indicates the increasing importance of flexibility and change as part and parcel of organisation's resilient responses to their environment. 
All three of the housing association providers have diversified their activities (some building on longer established plans). However, they do not all indicate an obvious shift in one direction on the commercial-social axis of the matrix. Several also go round the diversification question by entering into a range of more or less formal and more or less long term partnership relations with other forms of organisations. This is a way of managing risks with multiple stakeholders as well as delivering ether core or new services. While this is consistent with aspects of Mullins et al definition of hybridity, it is a more complex organisational form or set of relationships and not necessarily traditional diversification, as commonly understood.

The framework in Figure 2 is also useful for the different types of provider explored in this section. The case studies face a combination of external and internal risks and the demands of provider-specific stakeholders. They have all sought to develop and implement resilient responses involving governance reform (from prioritising risk management, establishing new boards to setting up group structures), they have taken different stances to the degree of diversification they felt necessary and indeed some have spread into more commercial as well as avowedly social enterprise activities. Much though not all of this can be explained by specific path dependencies.

\section{Concluding Discussion}

The approach taken in this paper was, in the face of the widely agreed set of new risks and uncertainties threatening social housing providers, to develop a simple conceptual framework (figure 2) that helped focus down on the individual social housing provider and how they respond to the environment they face. Primary research then tested the different ideas about risk, resilience, stakeholders and partners, social versus commercial impetus, core functions versus diversification through elite interviews with a representative group from across the Scottish housing sector followed by four diverse case studies that sought to capture the range of social housing providers in Scotland. Our fundamental research questions were:

- Which resilience strategies, including changing hybrid structures, are being developed by the sector and by case study providers in Scotland in response to the new risk or emerging risk environment?

- To what extent do the models applied in this paper help to inform this understanding?

Five key points emerged:

- A new constellation of old and new risks have arisen as the status quo in terms of funding and policy the previous 25 years came to an end. But external risks like funding shortages, austerity and welfare reform should be combined with internal risks associated with path dependency and the persistent influence of multiple stakeholders who exert varying degrees of external influence.

- The hybridity matrix (figure 1), based around axes of social or commercial focus and core versus diversification activities, is useful both positively (descriptively) and normatively (what providers and sector representatives think ought to be done). 
- Investing in risk management and building resilience capacity is not just a passive response to regulatory demands but reflects both a growing appreciation of the new operating environment and a desire to embed different notions of organisational resilience.

- Resilience is about organisational flexibility, strategic repurposing, good governance, evolution and learning - both across all levels of staffing but also in terms of a cultural openness to innovation, evidence and research. Operationally, frontline services and customer intelligence are reasserted as priorities.

- Social landlords are diverse in Scotland and, despite calls for consolidation, it is not obvious, even in the presence of the aforementioned risks and changed operating environment, that this situation will significantly or rapidly change. This is because context matters. Community-based housing, for instance, is a successful brand and often leads and anchors its neighbourhoods or rural catchment areas. Some landlords may diversify and others remain focused on core housing management activities and both models can perform to a high standard.

What does this research contribute to the hybridity debate outlined by Mullins, et al (2012) and the wider characterisation of organisational change in the sector? Does it suggest that hybridity is a useful theoretical concept? We believe it is a useful heuristic classificatory system that may inform policy debate but may not of itself identify the tensions and ambiguities that might flow from hybrid social housing organisations. We also think that the conceptual framework (figure 2) is also a useful device for isolating the range of forces operating on providers and how they may interact in a given context.

We conclude that, first, there is no sensible normative solution to where individual organisations should locate in the matrix. It depends on too many variables. Second, we would note that the multiple stakeholders role in shaping contemporary housing organisations may be persistent but it is also variable in terms of which ones matter, why and when. However, third, it does seem that many if not all developing social landlords are moving to hybrid financial and governance structures, if not hybrid products and services (in the sense used by Mullins et al). But it is the underlying path dependency of the organisation, its history, business setting and culture that determines the extent of hybridity and the preferred matrix location.

There remain a number of considerable challenges for the sector. First, particularly for housing associations, their very hybridity is an important ambiguity about the locus of control and appropriate classification of social housing. We have seen the ways in which regulators, government and lenders can shape and influence the direction of RSLs. English housing associations were re-classified because of the powers the regulator has over them. Reclassification means English housing association debt (more than £60 billion) is added to the national debt. The UK government is now, as we write, working out how to rapidly deregulate the English sector - the future of English social housing is, in that context, highly uncertain. None of this yet applies elsewhere in the UK but it is clearly a major source of external risk and the planned examination of the sector in the rest of the UK later in 2016 is likely to have a similar reclassification outcome (and subsequent similar deregulating response with further uncertain consequences). 
Second, and related, the Scottish sector as a whole needs to take a clear view of what the sector is for, whether it really embraces diversity (as we think it should), where it is located in the public-private spectrum and what the sense of the new established settlement should be for social housing? The 1989-2007 period is a distant memory now and there is no current or forward sense of stability or equilibrium, which is bad for business, for tenants, for meeting housing need and for housing system outcomes.

Third, while diversity is a strength, it also limits the effectiveness of government polices which remain insufficiently flexible to deal with the different needs and aspirations of the sector. In other words, it remains the case that policy seeks to support a small number of provider models but does not adequately acknowledge the diversity or the flexibility required to effectively work with different hybrid forms. Different providers represent combinations of the six features associated with the Mullins et al (2012) definition of hybridity. They are where they are because of context, path dependency and long term planning. Policy needs to offer an array of risk-proportionate tools to allow further diversification where it makes sense and to protect the efficient running of core services at the same time. Therefore, there can be no single preferred model of social housing but rather social housing policy redesign should enable and not prescribe diversity.

\section{References}

Audit Scotland (2013) Housing in Scotland, Edinburgh: Audit Scotland

Beck, U (1992) The Risk Society: Towards a New Modernity. SAGE: London.

Gibb, K (2013) "Market Signals, Planning and Social Housing", Town Planning Review, Volume 84 (1).

Gibb, K and McNulty, D (2014) Risk, Resilience and Effectiveness in the Non-Profit Sector: The Case of Housing Associations', Journal of Organizational Effectiveness: People and Performance, Vol. 1 (4) pp., 349-64

Gibb, K, McNulty, D and McLaughlin, T (2015) Reform, Risk and Resilience: Social Housing in Scotland. Policy Scotland/Wheatley Group: Glasgow

Gibb, K and Nygaard, C (2006) 'Transfers, Contracts and Regulation: A New Institutional Economics Perspective on the Changing Provision of Social Housing in Britain', Housing Studies, Vol. 21, pp.827-52.

Gruis, V (2008) 'Organisational archetypes for Dutch housing associations', Environment and Planning C: Government and Policy Vol. 26 (6), 1077-1092.

Hamel, G. and Valikangas, L. (2003) "The Quest for Resilience”, in Harvard Business Review, September 2003, Product 4910.

Housing Quality Network (2014) Resilience and Mental Toughness - In House Training email advertisement - Friday $14^{\text {th }}$ November 
Keynes, JM (1937) 'The General Theory of Employment', Quarterly Journal of Economics, pp.209-223.

Knight, F (1921) Risk, Uncertainty and Profit. Houghton Mifflin: Boston, Mass.

Maclennan, D. \& Chisholm, S. eds. (2013) New Times, New Businesses - Housing Provision in Times of Austerity, University of St Andrews, St Andrews

Mullins, D, Czischke, D and van Borterl, G (2012) 'Exploring the Meaning of Hybridity and Social Enterprise in Housing Organisations', Housing Studies, Vol. 27 (4) pp.405-17.

Mullins, D and Pawson, H (2010) Housing Associations: Agents of policy or profits in disguise? in Billis, D (ed) Hybrid Organisations and the Third sector: Challenges for Practice, Theory and Policy. Palgrave Macmillan: Basingstoke.

Priemus, H and Gruis, V (2011) 'Social housing and illegal state aid: The agreement between European commission and Dutch government', International Journal of Housing Policy Vol. 11 (1), 89-104.

Powell, R Dunnett, R Ferrari, E and McKee, K (2015) Affordable Housing Need in Scotland. Shelter/SFHA/CIH: Edinburgh.

Richardson, J., Barker, L., Furness, J., and Simpson, M. (2014) Frontline futures: New era, changing role for housing officers, Leicester: de Montfort University

Skelcher, C (2012) What do we mean when we talk about 'hybrids' and 'hybridity' in public management and governance? Working Paper pp.1-27 University of Birmingham, Institute of Local Government Studies.

Scottish Housing Regulator (2013) Regulatory Advice Note: Financial Risk and Viability, Scottish Housing Regulator, Glasgow http://www.scottishhousingregulator.gov.uk/publications/regulatory-advice-notefinancial-risk-and-viability

Scottish Housing Regulator (2014) Impact of Welfare Reform on rent arrears. Research Report 3, Scottish Housing Regulator, Glasgow http://www.scottishhousingregulator.gov.uk/sites/default/files/publications/Welfare \%20Reform \%20Survey\%203\%20-\%20Research\%20Report.pdf

Taylor, M. (2013) Securing Resilience, conference paper SFHA Finance Conference, November 2013

Underwood F., Kane, S. \& Appleby, M. (2014) Cosmopolitan Housing Group: Lessons Learned, Altair Consultancy and Advisory Services Ltd (commissioned by the Homes and Communities Agency (the Regulator) and Sanctuary Housing Group), London

Wilkinson, N. (2008) An Introduction to Behavioural Economics, Palgrave Macmillan, Basingstoke 
Zinn, J \& Taylor-Gooby, P (2006). Risk as an inter-disciplinary research area. In TaylorGooby \& Zinn (Eds.), Risk in social science. Oxford: Oxford University Press.

Zolli, A. and Healey, A-M. (2012) Resilience, Headline, London

Figure 1 Social Housing Archetypes

Defender

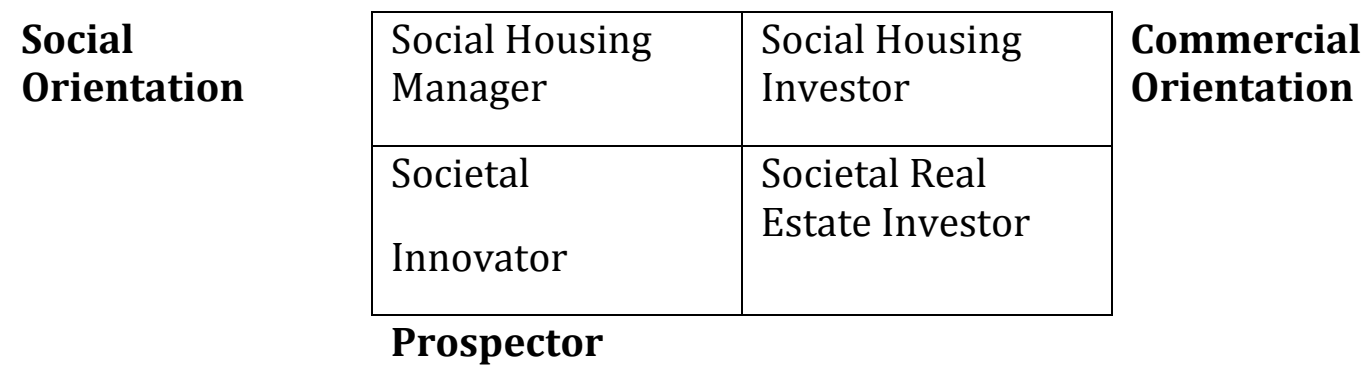

Source: derived from Gruis (2008) p.1081. 
Figure 2: Conceptualising Risk, Resilience and Reform in Contemporary Social Housing

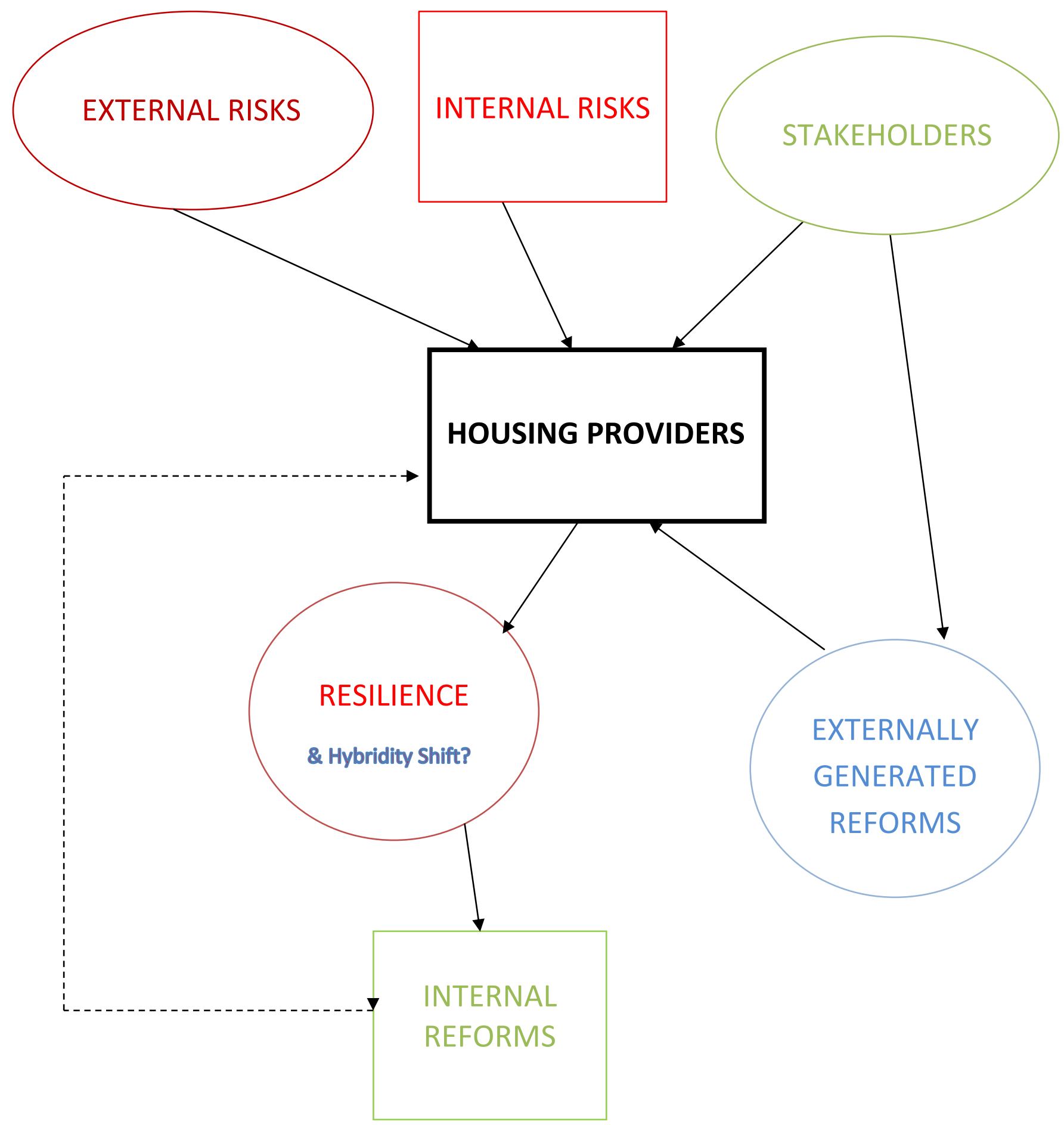


Table 1 Case Studies

\begin{tabular}{|c|c|c|c|c|}
\hline Social provider & Albyn Housing Society & $\begin{array}{l}\text { Cassiltoun Housing } \\
\text { association }\end{array}$ & Perth \& Kinross & Wheatley \\
\hline Typology & $\begin{array}{l}\text { RSL, rural, with non- } \\
\text { housing subsidiary }\end{array}$ & $\begin{array}{l}\text { Community-based } \\
\text { Glasgow RSL, with } \\
\text { subsidiary }\end{array}$ & $\begin{array}{l}\text { Urban-rural local authority } \\
\text { housing department }\end{array}$ & $\begin{array}{l}\text { Group structure RSL and } \\
\text { subsidiaries }\end{array}$ \\
\hline Number of units & $\begin{array}{l}2800 \text { across } 60 \\
\text { locations in the } \\
\text { Highlands }\end{array}$ & $\begin{array}{l}1171 \text { owned and } \\
\text { managed }\end{array}$ & c. 7500 units & $\begin{array}{l}\text { Over } 45,000 \text { units in RSL } \\
\text { subsidiaries: care } \\
\text { factoring. mid-market \& } \\
\text { market rented }\end{array}$ \\
\hline $\begin{array}{l}\text { Summary } \\
\text { description }\end{array}$ & $\begin{array}{l}\text { Subsidiary carries out } \\
\text { all of its non-charitable } \\
\text { activities, Albyn } \\
\text { Enterprises Ltd. Also } \\
\text { has established a joint } \\
\text { venture vehicle in } \\
\text { partnership with the } \\
\text { Calman Trust, Calbyn, } \\
\text { which looks to develop } \\
\text { and manage a } 124 \\
\text { bedroom social } \\
\text { enterprise hotel }\end{array}$ & $\begin{array}{l}\text { Community based } \\
\text { RSL and is } \\
\text { involved in a range } \\
\text { of non-housing } \\
\text { activities. Owns } \\
\text { Cassiltoun Trust, a } \\
\text { subsidiary set up } \\
\text { to renovate stables } \\
\text { and a Social } \\
\text { Enterprise pre-5 } \\
\text { nursery, Cassiltoun } \\
\text { Stables Nursery. }\end{array}$ & $\begin{array}{l}\text { Statutory council housing } \\
\text { provider for the Perth and } \\
\text { Kinross area }\end{array}$ & $\begin{array}{l}\text { Group Structure } \\
\text { comprises four social } \\
\text { landlords; a care } \\
\text { organisation and two } \\
\text { commercial subsidiaries; } \\
\text { factoring business and a } \\
\text { Private Rented Sector } \\
\text { company. }\end{array}$ \\
\hline Number of staff & c.70 & 20 (15 in nursery) & Not known & c.2100 \\
\hline Mission & $\begin{array}{l}\text { "Albyn Housing Society } \\
\text { serves an ever- } \\
\text { growing number of } \\
\text { communities in the } \\
\text { Highlands, providing } \\
\text { good quality, } \\
\text { affordable housing for } \\
\text { thousands of people } \\
\text { across the region" }\end{array}$ & $\begin{array}{l}\text { "We aim to } \\
\text { enhance the } \\
\text { quality of life of } \\
\text { our community } \\
\text { and to regenerate } \\
\text { our community } \\
\text { through housing- } \\
\text { led and resident- } \\
\text { controlled } \\
\text { initiatives." }\end{array}$ & $\begin{array}{l}\text { http://www.pkc.gov.uk/hou } \\
\text { sing }\end{array}$ & $\begin{array}{l}\text { "Making homes and lives } \\
\text { better" }\end{array}$ \\
\hline
\end{tabular}

